УДК 661.432:541.13

\title{
ПОТЕНЦИОМЕТРИЯ РЕАКЦИИ ДИОКСИДА ХЛОРА С ОСТАТОЧНЫМ ЛИГНИНОМ ЛИГНОЦЕЛЛЮЛОЗНОГО ПОРОШКОВОГО МАТЕРИАЛА
}

\author{
() К.С. Мухрыгин ${ }^{1 *}$ В.А. Демин ${ }^{1,2}$ \\ ${ }^{1}$ Институт химии Коми НЦ УрО РАН, ул. Первомайская, 48, Сыктывкар, \\ 167982 (Россия) \\ ${ }^{2}$ Сыктывкарский лесной институт, ул. Ленина, 39, Сыктывкар, 167982 \\ (Россия), e-mail: spiritsfolks@gmail.com
}

На основе измерений потенциала окислительно-восстановительной пары $\mathrm{ClO}_{2} / \mathrm{ClO}_{2}{ }^{-}$в водной суспензии лигноцеллюлозного порошкового материала изучена скорость расходования диоксида хлора на реакцию с остаточным лигнином. Отработана методика изучения кинетики реакции диоксида хлора с остаточным лигнином по модели первого порядка с варьированием начальной концентрации лигнина в реакционной смеси в пределах $(1 \div 17) \cdot 10^{-4} \mathrm{M}$ при начальной концентрации диоксида хлора $4,48 \cdot 10^{-4} \mathrm{M}$. В условиях избытка лигнина по зависимости $k_{\text {эф(I) }}=k_{\text {эф(II) }}[L]_{0}$ рассчитана монохронная константа скорости $k_{\text {эф(II) }}$ реакции второго порядка диоксида хлора с остаточным лигнином, равная $1462 \pm 108 \mathrm{M}^{-1} \mathrm{c}^{-1}$. С учетом начальных концентраций реагентов выявлено, что по мере увеличения степени превращения лигнина $\Theta$ от $\approx 0,27$ до 0,54 его реакционная способность при взаимодействии с диоксидом хлора снижается,

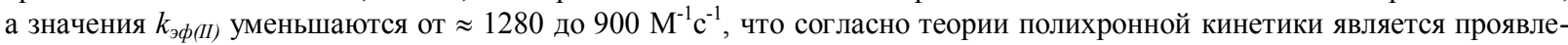
нием кинетической неэквивалентности различных ансамблей макромолекул остаточного лигнина. Таким образом, впервые экспериментально показано, что остаточный лигнин лигноцеллюлозного порошкового материала обладает кинетической неэквивалентностью при взаимодействии с диоксидом хлора.

Ключевые слова: потенциометрия, кинетика, константа скорости, лигноцеллюлозный порошковый материал, остаточный лигнин, диоксид хлора, кинетическая неоднородность.

\section{Введение}

Диоксид хлора - важнейший окислительный реагент, широко используемый в ECF (Elemental Chlorine Free) отбелке технической целлюлозы [1], водоподготовке [2] и органическом синтезе [3]. Его реакции с лигнином как правило изучают в гомогенных условиях на модельных соединениях лигнина $[4,5]$, при этом кинетика реакций лигнинов в гетерогенных условиях остается малоизученной, так как чаще всего ее изучают по эффекту делигнификации. В качестве кинетических моделей используют (формально) уравнения односторонних реакций первого порядка, топохимические уравнения Колмогорова-Ерофеева и др., а также уравнения диффузионной и полихронной кинетики [6, 7]. Причиной этого является существенная сложность процессов делигнификации, неопределенность понятия моль лигнина и необходимость использования косвенных методов определения его содержания в лигноцеллюлозном материале. Особенно сложно изучение кинетики реакций лигнина в процессах отбелки целлюлозы, так как получить достоверную информацию при низком содержании лигнина на основе стандартных методов затруднительно или трудоемко (жесткость по Бъеркману, число Каппа или фотометрия [8]).

В изучении кинетики реакций лигнина, протекающих относительно медленно и при высокой температуре, достигнут существенный прогресс и установлены особенности реакционной способности лигнина.

Мухрыгин Кирилл Сергеевич - аспирант, младший научный сотрудник лаборатории химии растительных полимеров, e-mail: bumblepc@mail.ru

Демин Валерий Анатольевич - заведующий кафедрой ЦБП, ЛХ и ПЭ, профессор; доктор химических наук, главный научный сотрудник лаборатории химии растительных полимеров, e-mail: demin@sfi.komi.com
Из-за молекулярно-структурной неоднородности лигнина и особенностей его локализации в полимерной углеводной матрице кинетические закономерности реакций лигнина в процессах варки и отбелки целлюлозы отличаются полихронностью [911]. Наиболее изучены проявления кинетической

\footnotetext{
* Автор, с которым следует вести переписку.
} 
неоднородности лигнинов при взаимодействии со щелочами [12-15], азотной кислотой [6, 16] и пероксиреагентами $[7,9]$, т.е. в относительно медленно протекающих реакциях. Аналитической основой этих работ служили данные по изменению концентрации лигнина в пробах целлюлозного материала, а процесс в целом рассматривался преимущественно как односторонний по лигнину.

Однако кинетика реакций лигнина с диоксидом хлора, протекающих быстрее реакций варки на один-два порядка, остается малоизученной, отчасти из-за того что концентрацию диоксида хлора долгое время определяли методом иодометрии [17], а более оперативные спектральные методы измерения малопригодны для гетерогенных систем [18]. В данной работе использован метод потенциометрии раствора диоксида хлора, предложенный ранее для исследования быстропротекающих реакций кислородных соединений хлора с остаточным лигнином $[19,20]$.

При взаимодействии диоксида хлора с алкилароматическими углеводородами (RH), в том числе с лигнином, осуществляется перенос электрона от $\mathrm{RH}$ к $\mathrm{ClO}_{2}$ с образованием углеводородного катионрадикала и хлорит-иона [21]:

$$
\mathrm{RH}+\mathrm{ClO}_{2} \rightarrow \mathrm{RH}^{\bullet+}+\mathrm{ClO}_{2}^{-} .
$$

Для одноэлектронного перехода уравнение Нернста имеет вид [22]:

$$
\varphi=\varphi_{\mathrm{ClO}_{2} / \mathrm{ClO}_{2}^{-}}^{0}+R T \cdot \ln \frac{a_{\mathrm{ClO}_{2}}}{a_{\mathrm{ClO}_{2}^{-}}}
$$

Стандартный потенциал пары $\mathrm{ClO}_{2} / \mathrm{ClO}_{2}^{-}$отвечает значению +745 мВ относительно хлорсеребряного электрода [22]. Прямо пропорциональная зависимость $\varphi-\ln \left[\mathrm{ClO}_{2}\right]$ позволяет использовать ее для кинетического анализа в интервале значений $+745 \div 660$ мВ. Снижение величины потенциала по ходу реакции с лигнином (в суспензии целлюлозы в воде) позволяет заключить, что именно одноэлектронный переход «диоксид хлора - хлорит-ион» является лимитирующей стадией.

Современные приборы и программное обеспечение позволяют по-новому подойти к исследованию окислительных процессов, в частности процессов отбелки сульфатной целлюлозы, обнаружить новые способы применения потенциометрии в решении исследовательских и прикладных задач.

Объектом исследования является остаточный лигнин лигноцеллюлозного порошкового материала (ЛЦП), который получают путем гидролитической обработки небеленой целлюлозы [23, 24] и (или) других содержащих лигнин видов растительного сырья [25] разбавленными минеральными кислотами до предельной степени полимеризации. ЛЦП представляют интерес в качестве сорбентов, антиоксидантов, носителей лекарственных форм, а также как полупродукты при получения микро- и наноцелюлозных материалов для темплатного синтеза керамики [26] и для химической модификации [27, 28].

Целью данной работы является отработка методики потенциометрического изучения реакции диоксида хлора с остаточным лигнином лигноцеллюлозного порошкового материала.

\section{Экспериментальная часть}

Лигноцеллюлозный порошковый материал получали путем обработки небеленой хвойной сульфатной целлюлозы 10\%-ной серной кислотой при температуре кипения смеси с гидромодулем $16: 1$ в течение 2 ч. Затем остаток промывали водой и высушивали. Содержание лигнина Комарова составляло 7,6\%.

В опытах использовали диоксид хлора, полученный в промышленных условиях по технологии «НР-А» на АО «Монди СЛПК» (восстановлением хлората пероксидом водорода). Реакцию остаточного лигнина с диоксидом хлора изучали при постоянной начальной концентрации $\mathrm{ClO}_{2} 4,48 \cdot 10^{-4} \mathrm{M} \mathrm{c} \mathrm{варьиро-}$

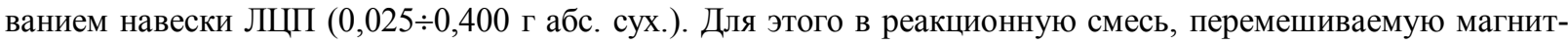
ной мешалкой суспензию ЛЦП, общим объемом 100 мл добавляли 0,40 мл исходного раствора диоксида хлора концентрацией $1,12 \cdot 10^{-2} \mathrm{M}$ (7,56 г/л по иодометрическому методу). Общие условия: $\mathrm{pH}=3,5$ (отвечает режиму делигнификации в промышленной отбелке целлюлозы), температура $25^{\circ} \mathrm{C}$. Потенциометрические измерения осуществляли с помощью прибора «Мультитест ИПЛ-103», оснащенного комбинированным электродом типа ЭСК-10601/7 и подключенного к персональному компьютеру. Данные измерений записывались при помощи программного обеспечения, поставляемого с прибором. 
Начальные концентрации реагентов в различных опытах были выбраны таким образом, чтобы обеспечить избыток как лигнина, так и диоксида хлора в реакционной смеси. Начальную концентрацию остаточного лигнина в суспензии лигноцеллюлозного порошкового материала из небеленой хвойной сульфатной целлюлозы рассчитывали по формуле:

$$
[L]_{0}=\frac{m \cdot L}{M(\Phi \Pi E) \cdot V},
$$

где $m$ - масса навески ЛЦП в пересчете на абсолютно сухой материал, г; $L$ - содержание лигнина, \%; $M(Ф П E)=182,5$ - молекулярная масса фенилпропановой единицы гваяцильного типа, Да [10]; $V-$ объем реакционной смеси, л.

\section{Обсуждение результатов}

Зависимость окислительно-восстановительного потенциала $\varphi$ от времени $\tau$ для опытов 1-7 приведена на рисунке 1. Экспериментальные точки сняты с шагом 1 с.

Значения концентраций реагентов для серии опытов указаны в таблице 1. Разность начальных концентраций диоксида хлора и лигнина приведена для использования кинетических расчетов. Первые 4 опыта отвечают избытку диоксида хлора, последние 3 - избытку остаточного лигнина.

В случае избытка органического субстрата (лигнина) реакцию можно анализировать, как реакцию псевдопервого порядка по диоксиду хлора. Значения тангенса наклона кривых на участке линеаризации (коэффициента В, табл. 2) для случая избытка субстрата являются константами скоростей реакций псевдопервого порядка, они находятся в пределах $(3,25 \div 156,50) \cdot 10^{-2} \mathrm{c}^{-1}$ и зависят от начальной концентрации лигнина в реакционной смеси (рис. 2).

Рис. 1. Экспериментальные значения

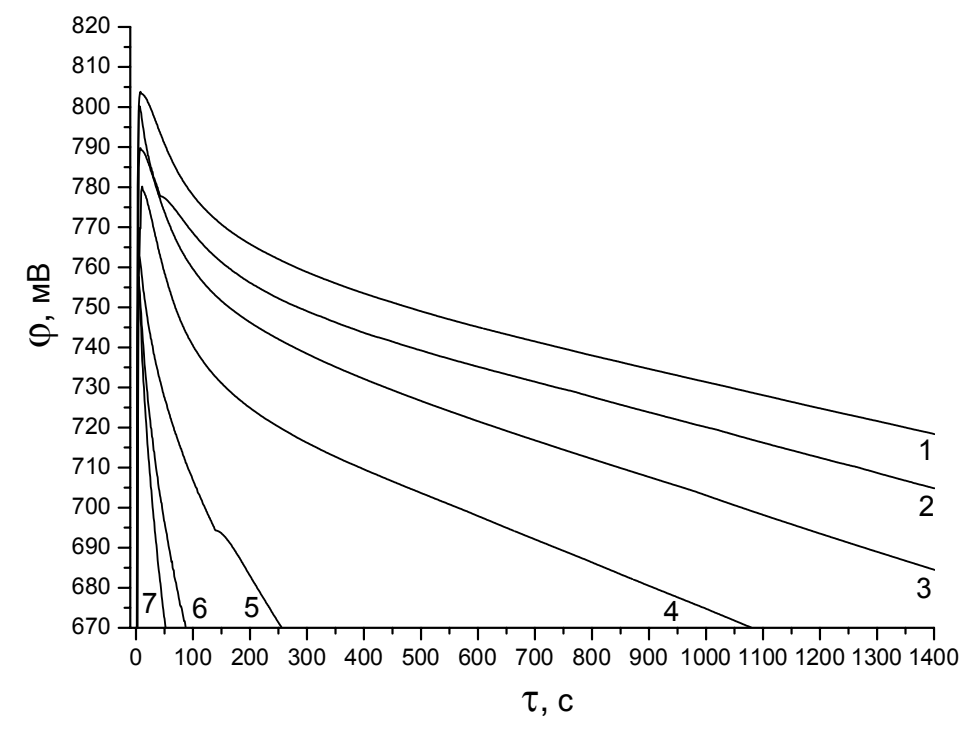

(точки) зависимости « $\varphi-\tau »$

Таблица 1. Начальные концентрации реагентов

\begin{tabular}{l|c|c|c}
\hline $\begin{array}{c}\text { № } \\
\text { опыта }\end{array}$ & $\begin{array}{c}\text { Аналитическая навеска в пере- } \\
\text { счете на абс. сух. материал, } \Gamma\end{array}$ & $\begin{array}{c}\text { Начальная* концентрация оста- } \\
\text { точного лигнина }[\mathrm{L}]_{0}, \mathrm{M} \cdot 10^{4}\end{array}$ & $\begin{array}{c}\text { Разность начальных мольных концен- } \\
\text { траций реагентов }[\mathrm{L}]_{0}-[\mathrm{ClO}]_{0}, \mathrm{M} \cdot 10^{4}\end{array}$ \\
\hline 1 & 0,025 & 1,04 & $-3,44$ \\
2 & 0,033 & 1,37 & $-3,11$ \\
3 & 0,050 & 2,08 & $-2,40$ \\
4 & 0,100 & 4,16 & $-0,32$ \\
5 & 0,200 & 8,33 & 3,85 \\
6 & 0,300 & 12,49 & 8,01 \\
7 & 0,400 & 16,66 & 12,20 \\
\hline
\end{tabular}

*Расчетная - без округлений. 
Таблица 2. Результаты статистической обработки данных потенциометрии по уравнению типа $y=A+B x$

\begin{tabular}{|c|c|c|c|c|c|c|}
\hline \multirow{2}{*}{ № } & \multicolumn{2}{|c|}{ Участок линеаризации } & \multirow{2}{*}{$A$} & \multirow{2}{*}{$\pm \triangle A$} & \multirow{2}{*}{$-B \cdot 10^{2}$} & \multirow{2}{*}{$\pm \triangle B \cdot 10^{2}$} \\
\hline & $\varphi, \mathrm{MB}$ & $\varphi, \mathrm{MB}$ & & & & \\
\hline 1 & 745 & 730 & 720,06 & 0,01 & 3,25 & 0,01 \\
\hline 2 & 720 & 680 & 720,04 & 0,01 & 3,79 & 0,01 \\
\hline 3 & 720 & 680 & 719,81 & 0,01 & 4,85 & 0,01 \\
\hline 4 & 720 & 680 & 720,02 & 0,01 & 8,25 & 0,01 \\
\hline 5 & 720 & 680 & 719,34 & 0,10 & 34,70 & 0,23 \\
\hline 6 & 720 & 680 & 718,32 & 0,28 & 87,90 & 1,06 \\
\hline 7 & 715 & 680 & 715,28 & 0,24 & 156,50 & 1,96 \\
\hline
\end{tabular}

Зависимость « $k_{\ni \phi(I)}-[L]_{0} »$ криволинейна. В области $[L]_{0} \gg\left[C l O_{2}\right]_{0}$, т.е. справа от пунктирной линии на рисунке 2 , реакция по диоксиду хлора является псевдомономолекулярной, при $[L]_{0} \leq\left[\mathrm{ClO}_{2}\right]_{0}$ скорость поглощения диоксида хлора субстратом отвечает второму порядку в соответствии с $v=k_{э \phi(I I)}\left[\mathrm{ClO}_{2}\right][L]$.

В зависимости от соотношения начальных концентраций реагентов - остаточного лигнина и диоксида хлора - могут быть реализованы различные способы расчета констант скоростей реакций по модели второго порядка $k_{\ni ф(I I)}$.

Обычным приемом является использование одного из реагентов в большом избытке, например лигнина. При этом значения констант скоростей химической реакции второго порядка будут выглядеть монохронными и однозначно характеризовать начальные, наиболее «быстрые» ансамбли макромолекул лигнина. При этом варьированием концентрации избыточного реагента определяют значение константы скорости реакции второго порядка.

Для опытов 5-7 по зависимости $k_{\ni \phi(I)}=k_{э \phi(I I)}[L]_{0}$, приведенной на рисунке 3 , получаем: $k_{\ni \phi(I I)}=1462 \pm$ $108 \mathrm{M}^{-1} \mathrm{c}^{-1}$ (коэф. корр. 0,997).

Во втором случае, с учетом начальных концентраций реагентов, по мере уменьшения глубины превращения остаточного лигнина за счет уменьшения доли окислителя - диоксида хлора - в реакционной смеси значения констант скоростей увеличиваются и появляется возможность оценить распределение ансамблей лигнина по константам скоростей, т.е. оценить кинетическую неэквивалентность остаточного лигнина (табл. 3).

Расчет проводят по модели второго порядка с учетом начальных концентраций обоих реагентов исходя из уравнений [29]:

$$
\begin{gathered}
-\frac{d C_{A}}{d t}=-\frac{d C_{B}}{d t}=k_{2} C_{A} C_{B}, \\
\frac{d x}{d t}=k_{2}(a-x)(b-x),
\end{gathered}
$$

где $a$ и $b$ - начальные концентрации реагентов (лигнина - моль ФПЕ и диоксида хлора). Кинетические кривые при этом линеаризуются в координатах

$$
k_{2}=\frac{1}{\tau(a-b)} \ln \frac{(a-x) b}{(b-x) a} .
$$

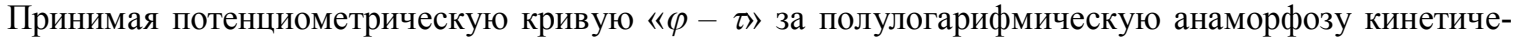
ской кривой, по тангенсу угла наклона и разности начальных концентраций реагентов находим константу скорости:

$$
k_{\ni \phi(I I)}=\frac{\operatorname{tg} \alpha}{\Delta C},
$$

где $\Delta C=a-b=[L]_{0}-\left[\mathrm{ClO}_{2}\right]_{0}$ (табл. 1,3$)$.

По мере увеличения максимальной степени превращения лигнина $\Theta$, которую рассчитывали по мольному отношению реагентов $\Theta=\left[\mathrm{ClO}_{2}\right]_{0} /[L]_{0}$, значение $k_{\text {эф(II) }}$ снижается от $\approx 1280$ до $900 \mathrm{M}^{-1} \mathrm{c}^{-1}$ при изменении $\Theta$ в два раза - от $\approx 0,27$ до 0,54 . Это характеризует кинетическую неоднородность остаточного лигнина лигноцеллюлозного порошка в реакции с диоксидом хлора. 


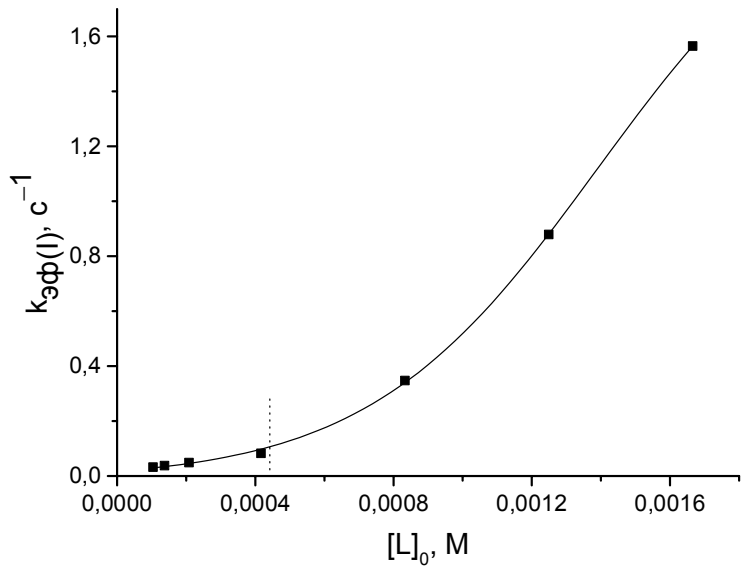

Рис. 2. Общий вид зависимости «k $k_{э \phi(I)}-[L]_{0} »$. Пунктирная линия соответствует эквимолярному отношению концентраций реагентов

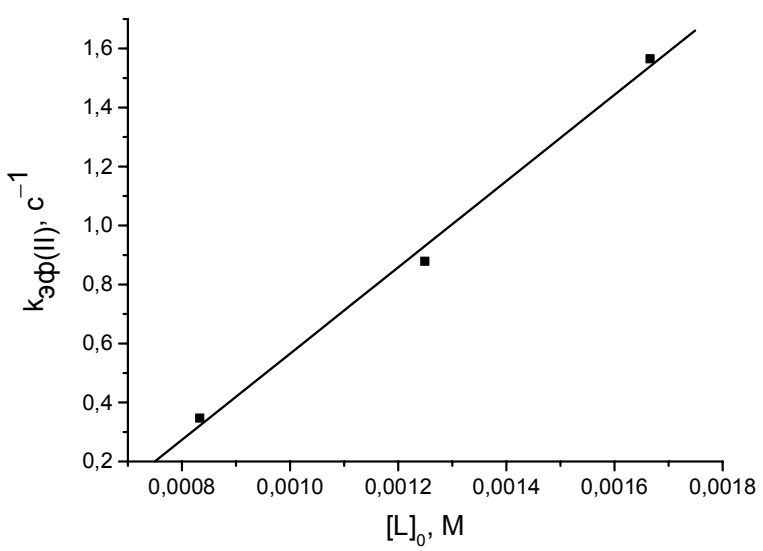

Рис. 3. Линеаризация зависимости « $k_{э ф(I)}-[L]_{0} »$ для расчета $k_{э ф(I I)}$ по опытам 5-7

Таблица 3. Константы скорости и степень превращения лигнина

\begin{tabular}{c|c|c|c|c|c}
\hline № опыта & {$[L]_{0}, \mathrm{M} \cdot 10^{4}$} & $\Delta C, \mathrm{M} \cdot 10^{4}$ & $k_{\text {эф(I) }}, \mathrm{c}^{-1} \cdot 10^{2}$ & $k_{\text {эф(II) }}, \mathrm{M}^{-1} \mathrm{c}^{-1}$ & $\Theta$ \\
\hline 5 & 8,33 & 3,85 & 34,70 & 900 & 0,538 \\
7 & 12,49 & 8,01 & 87,90 & 1100 & 0,359 \\
\hline
\end{tabular}

$\Theta-$ степень превращения лигнина.

\section{Выводы}

1. Отработана методика изучения кинетики быстропротекающих реакций лигнинов с участием диоксида хлора по модели первого и второго порядка со стороны окислителя. Рабочим диапазоном начальных мольных концентраций $\mathrm{ClO}_{2}$ является $\sim 10^{-3} \div 10^{-5} \mathrm{M}$.

2. Монохронная константа скорости $k_{\text {эф(II) }}$ реакции диоксида хлора с остаточным лигнином порошкового материала из небеленой хвойной сульфатной целлюлозы, определенная с использованием потенциометрического метода в условиях избытка лигнина в реакционной смеси, составляет $1462 \pm 108 \mathrm{M}^{-1} \mathrm{c}^{-1}$.

3. С учетом начальных концентраций реагентов выявлено, что по мере увеличения степени превращения лигнина $\Theta$ от $\approx 0,27$ до 0,54 его реакционная способность при взаимодействии с диоксидом хлора

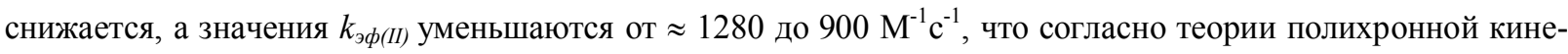
тики является проявлением кинетической неэквивалентности различных ансамблей макромолекул остаточного лигнина.

\section{Список литературы}

1. Sixta H. Handbook of pulp. Vol. 1. Weinheim, 2006. 1352 p.

2. Швецов А.Б., Козырева А.В., Седунов С.Г., Тараскин К.А. Хлорные дезинфектанты и их применение в современной водоподготовке // Молекулярные технологии. 2009. Т. 3. С. 98-121.

3. Кучин А.В., Рубцова С.А., Судариков Д.В., Демакова М.Я. Диоксид хлора в реакциях хемо- и стереоселективного окисления сульфидов // Известия Академии наук. Серия химическая. 2013. №1. С. 1-5.

4. Elder T. Reactions of lignin model compounds with chlorine dioxide. Molecular orbital calculations // Holzforschung. 1998. Vol. 52. N4. Pp. 371-384.

5. Singh A. Mechanism of reaction chlorine, chlorine dioxide and nitrogen // J. Of pulp and paper science. 1990. Vol. 16. N2. Pp. 48-53.

6. Белькова Л.П., Громов В.С., Михайлов А.И. Полихронная кинетика процессов делигнификации древесины. 2. Диффузионная кинетика азотнокислой делигнификации // Химия древесины. 1980. №6. С. 59-64.

7. Карманов А.П., Демин В.А. Кинетика делигнификации древесины в процессах варки и отбелки целлюлозы // Химия в интересах устойчивого развития. 1996. №4. С. 289-298. 
8. Оболенская А.В., Ельницкая 3.П., Леонович А.А. Лабораторные работы по химии древесины и целлюлозы: учебное пособие для вузов. М., 1991. 320 с.

9. Демин В.А. Теоретические основы отбелки целлюлозы. СПб., 2013. 100 с.

10. Карманов А.П. Самоорганизация и структурная организация лигнина. Екатеринбург, 2004. 269 с.

11. Щербакова Т.П., Михайлов А.И., Демин В.А. Полихронная кинетика делигнификации сульфатной целлюлозы // Журнал прикладной химии. 2004. Т. 77, №10. С. 1739-1742.

12. Пен Р.3., Шапиро И.Л., Пен В.Р. Аппроксимация уравнений полихронной кинетики натронной варки сосны // Химия древесины. 1990. №3. С. 33-40.

13. Пен Р.З., Шапиро И.Л., Пен В.Р., Катрухина М.Ю. Сравнение методов определения параметров полихронной кинетики процесса щелочной делигнификации // Химия древесины. 1992. № 4-5. С. 31-35.

14. Пен Р.З., Шапиро И.Л., Пен В.Р. Кинетический компенсационный эффект в процессе щелочной делигнификации // Химия древесины. 1990. №5. С. 106.

15. Вершаль В.В., Чупка Э.И., Ушаковский О.В., Михайлов А.И. Полихронная кинетика процессов делигнификации. 4. Процесс щелочной делигнификации древесины сосны с добавками антрахинона и сульфида натрия // Химия древесины. 1988. №6. С. 47-50.

16. Белькова Л.П., Громов В.С., Михайлов А.И. Полихронная кинетика процессов делигнификации древесины. 1. Процесс азотнокислой делигнификации // Химия древесины. 1980. №6. С. 50-58.

17. Vogel A.I. Text book of quantitative chemical analysis, fifth ed. New York, 1989. Pp. 390-394.

18. Кузиванов И.М., Садыков Р.А., Судариков Д.В., Кучин А.В. Кинетика окисления диметилсульфоксида диоксидом хлора // Известия Коми научного центра УрО РАН. 2015. Вып. 4(24). С. 24-27.

19. Демин В.А., Липин И.В. Потенциометрический метод исследования кинетики гетерогенных реакций с участием диоксида хлора // Международное научное издание «Современные фундаментальные и прикладные исследования». 2011. №3. С. 101-106.

20. Липин И.В., Демин В.А. Кинетика реакции диоксида хлора с остаточным лигнином лиственной сульфатной целлюлозы // Известия Коми научного центра УрО РАН. 2012. Вып. 4 (16). С. 21-24.

21. Тимергазин К. К. Интермедиаты в реакциях диоксида хлора и озона с органическими соединениями : автореф. дис. ... канд. хим. наук. Уфа, 2000. 21 с.

22. Туманова Т.А. Физико-химические основы отбелки целлюлозы. М., 1984. 216 с.

23. Казакова Е.Г., Дёмин В.А. Получение порошковой целлюлозы // Журнал прикладной химии. 2009. Т. 82, вып. 6. С. 1033-1036.

24. Казакова Е.Г., Демин В.А. Новый способ получения микрокристаллической целлюлозы // Журнал прикладной химии. 2009. Т. 82, вып. 3. С. 502-505.

25. Удоратина Е.В., Демин В.А. Получение лигноцеллюлозного порошкового материала из вторичного сырья // Журнал прикладной химии. 2007. Т. 80, вып. 1. С. 119-122.

26. Мартаков И.С., Кривошапкин П.В., Торлопов М.А., Кривошапкина Е.Ф., Демин В.А. Влияние надмолекулярной структуры целлюлозы на морфологию волокон оксида алюминия, полученного золь-гель методом // Химия в интересах устойчивого развития. 2014. Т. 22, №2. С. 145-151.

27. Торлопов М.А., Фролова С.В., Демин В.А. Сульфатирование порошковых материалов, полученных деструкцией целлюлозы тетрахлоридом титана // Химия в интересах устойчивого развития. 2007. Т. 15, №4. С. 491-496.

28. Торлопов М.А., Демин В.А. Сульфатированные и карбоксиметилированные производные микрокристаллической целлюлозы // Химия растительного сырья. 2007. №3. С. 55-61.

29. Эмануэль Н.М., Кнорре Д.Г. Курс химической кинетики. М., 1974. 400 с.

Поступило в редакиию 25 апреля 2016 г.

После переработки 2 июня 2016 г. 
Mukhrygin K.S. ${ }^{1 *}$, Demin V.A. ${ }^{1,2}$ THE REACTION POTENTIOMETRY OF RESIDUAL LIGNIN OF LIGNOCELLULOSE POWDER MATERIAL WITH CHLORINE DIOXIDE

${ }^{1}$ Institute of Chemistry, Komi Science Centre, ul. Pervomayskaya, 48, Syktyvkar, 167982 (Russia)

${ }^{2}$ Syktyvkar Forest Institute, ul. Lenina, 39, Syktyvkar, 167982 (Russia),e-mail: spiritsfolks@gmail.com

The consumption rate of chlorine dioxide to react with residual lignin was studied on the basis of redox couple $\mathrm{ClO}_{2} / \mathrm{ClO}_{2}^{-}$potential measurements in lignocellulose powder material aqueous suspension. The methodology for the study of reaction kinetics of chlorine dioxide with the residual lignin was perfected by the first order reaction model with the initial lignin concentration in the reaction medium varying in the range of $(1 \div 17) \cdot 10^{-4} \mathrm{M}$ at the initial chlorine dioxide concentration of $4,48 \cdot 10^{-4} \mathrm{M}$. The monochrome rate constant of the second order reaction of chlorine dioxide with the residual lignin was calculated by the dependence $k_{e f(I)}=k_{e f(I)}[L]_{0}$ under excess lignin conditions and equaled $1462 \pm 108 \mathrm{M}^{-1} \mathrm{~s}^{-1}$. It was found that if the lignin conversation degree $\Theta$ increases from $\approx 0,27$ to 0,54 , taking into account the initial concentrations of the reagents; its reactivity in reaction with chlorine dioxide reduces and $k_{\text {ef(II) }}$ value decreases from $\approx 1280$ to $980 \mathrm{M}^{-1} \mathrm{~s}^{-1}$, that according to the theory polychronal kinetics is a manifestation of kinetic non-equivalence of the various residual lignin macromolecules assemblies. Thus it was first shown experimentally that the residual lignin of lignocellulose powder material has kinetic nonequivalence in reaction with chlorine dioxide.

Keywords: potentiometry, kinetics, rate constant, lignocellulose powder material, residual lignin, chlorine dioxide, kinetic heterogeneit.

\section{References}

1. Sixta H. Handbook of pulp, vol. 1, Weinheim, 2006, 1352 p.

2. Shvetsov A.B., Kozyreva A.V., Sedunov S.G., Taraskin K.A. Molekuliarnye tekhnologii, 2009, vol. 3, pp. 98-121. (in Russ.).

3. Kuchin A.V., Rubtsova S.A., Sudarikov D.V., Demakova M.Ia. Izvestiia Akademii Nauk. Seriia khimicheskaia, 2013, no. 1, pp. 1-5. (in Russ.).

4. Elder T. Holzforschung, 1998, vol. 52, no. 4, pp. 371-384.

5. Singh A. J. Of pulp and paper science, 1990, vol. 16, no. 2, pp. 48-53.

6. Bel'kova L.P., Gromov V.S., Mikhailov A.I. Khimiia drevesiny, 1980, no. 6, pp. 59-64. (in Russ.).

7. Karmanov A.P., Demin V.A. Khimiia v interesakh ustoichivogo razvitiia, 1996, no. 4, pp. 289-298. (in Russ.).

8. Obolenskaia A.V., El'nitskaia Z.P., Leonovich A.A. Laboratornye raboty po khimii drevesiny i tselliulozy: Uchebnoe posobie dlia vuzov. [Laboratory work on the chemistry of wood and cellulose: A manual for schools]. Moscow, 1991, 320 p. (in Russ.).

9. Demin V.A. Teoreticheskie osnovy otbelki tselliulozy. [Theoretical Foundations of pulp bleaching]. SPb, 2013,100 p. (in Russ.).

10. Karmanov A.P. Samoorganizatsiia $i$ strukturnaia organizatsiia lignina. [Self-organization and structural organization of the lignin]. Ekaterinburg, 2004, 269 p. (in Russ.).

11. Shcherbakova T.P., Mikhailov A.I., Demin V.A. Zhurnal prikladnoi khimii, 2004, vol. 77, no. 10, pp. 1739-1742. (in Russ.).

12. Pen R.Z., Shapiro I.L., Pen V.R. Khimiia drevesiny, 1990, no. 3, pp. 33-40. (in Russ.).

13. Pen R.Z., Shapiro I.L., Pen V.R., Katrukhina M.Iu. Khimiia drevesiny, 1992, no. 4-5, pp. 31-35. (in Russ.).

14. Pen R.Z., Shapiro I.L., Pen V.R. Khimiia drevesiny, 1990, no. 5, p. 106. (in Russ.).

15. Vershal' V.V., Chupka E.I., Ushakovskii O.V., Mikhailov A.I. Khimiia drevesiny, 1988, no. 6, pp. 47-50. (in Russ.).

16. Bel'kova L.P., Gromov V.S., Mikhailov A.I. Khimiia drevesiny, 1980, no. 6, pp. 50-58. (in Russ.).

17. Vogel A.I. Text book of quantitative chemical analysis, fifth ed. New York, 1989, pp. 390-394.

18. Kuzivanov I.M., Sadykov R.A., Sudarikov D.V., Kuchin A.V. Izvestiia Komi nauchnogo tsentra UrO RAN, 2015, no. 4(24), pp. 24-27. (in Russ.).

19. Demin V.A., Lipin I.V. Mezhdunarodnoe nauchnoe izdanie «Sovremennye fundamental'nye $i$ prikladnye issledovaniia». [International scientific publication "Modern basic and applied research"]. 2011, no. 3, pp. $101-106$. (in Russ.).

20. Lipin I.V., Demin V.A. Izvestiia Komi nauchnogo tsentra UrO RAN, 2012, no. 4(16), pp. 21-24. (in Russ.).

21. Timergazin K.K. Intermediaty v reaktsiiakh dioksida khlora i ozona s organicheskimi soedineniiami. Avtoref. dis. ... kand. khim. nauk. [Intermediates in the reactions of chlorine dioxide and ozone with organic compounds. Author. Dis. ... Cand. Chem. sciences]. Ufa, 2000, 21 p. (in Russ.).

22. Tumanova T.A. Fiziko-khimicheskie osnovy otbelki tselliulozy. [Physical and chemical bases of pulp bleaching]. Moscow, 1984, 216 p. (in Russ.).

23. Kazakova E.G., Demin V.A. Zhurnal prikladnoi khimii, 2009, vol. 82, no. 6, pp. 1033-1036. (in Russ.).

24. Kazakova E.G., Demin V.A. Zhurnal prikladnoi khimii, 2009, vol. 82, no. 3, pp. 502-505. (in Russ.).

25. Udoratina E.V., Demin V.A. Zhurnal prikladnoi khimii, 2007, vol. 80, no. 1, pp. 119-122. (in Russ.).

26. Martakov I.S., Krivoshapkin P.V., Torlopov M.A., Krivoshapkina E.F., Demin V.A. Khimiia $v$ interesakh ustoichivogo razvitiia, 2014, vol. 22, no. 2, pp. 145-151. (in Russ.).

27. Torlopov M.A., Frolova S.V., Demin V.A. Khimiia v interesakh ustoichivogo razvitiia, 2007, vol. 15, no. 4, pp. 491-496. (in Russ.).

28. Torlopov M.A., Demin V.A. Khimiia rastitel'nogo syr'ia, 2007, no. 3, pp. 55-61. (in Russ.).

29. Emanuel' N.M., Knorre D.G. Kurs khimicheskoi kinetiki. [Chemical Kinetics Course]. Moscow, 1974, 400 p. (in Russ.).

Received April 25, 2016

Revised June 2, 2016

\footnotetext{
* Corresponding author.
} 
